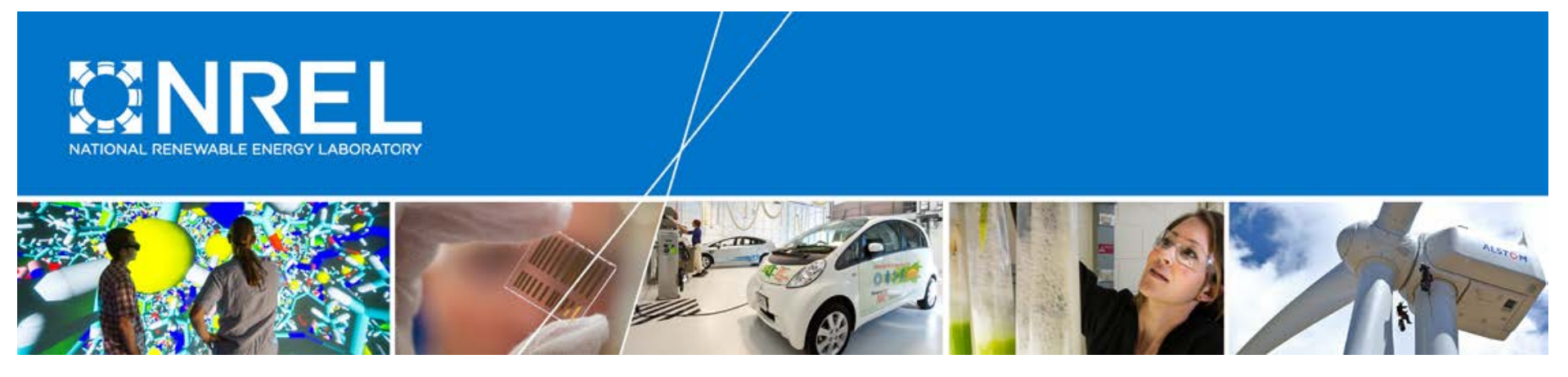

\title{
Methods for Analyzing the Economic Value of Concentrating Solar Power with Thermal Energy Storage
}

Paul Denholm, Jennie Jorgenson, Mackay Miller, and Ella Zhou National Renewable Energy Laboratory

Caixia Wang

State Grid Energy Research Institute

NREL is a national laboratory of the U.S. Department of Energy Office of Energy Efficiency \& Renewable Energy Operated by the Alliance for Sustainable Energy, LLC

This report is available at no cost from the National Renewable Energy Laboratory (NREL) at www.nrel.gov/publications.

Technical Report

NREL/TP-6A20-64256

July 2015

Contract No. DE-AC36-08GO28308 


\section{Methods for Analyzing the Economic Value of Concentrating Solar Power with Thermal Energy Storage}

Paul Denholm, Jennie Jorgenson, Mackay Miller, and Ella Zhou National Renewable Energy Laboratory

Caixia Wang

State Grid Energy Research Institute

Prepared under Task No. IGIN.1880

NREL is a national laboratory of the U.S. Department of Energy Office of Energy Efficiency \& Renewable Energy Operated by the Alliance for Sustainable Energy, LLC

This report is available at no cost from the National Renewable Energy Laboratory (NREL) at www.nrel.gov/publications.

National Renewable Energy Laboratory 15013 Denver West Parkway Golden, CO 80401

303-275-3000 • www.nrel.gov

\section{Technical Report}

NREL/TP-6A20-64256

July 2015

Contract No. DE-AC36-08G028308 


\title{
NOTICE
}

This report was prepared as an account of work sponsored by an agency of the United States government. Neither the United States government nor any agency thereof, nor any of their employees, makes any warranty, express or implied, or assumes any legal liability or responsibility for the accuracy, completeness, or usefulness of any information, apparatus, product, or process disclosed, or represents that its use would not infringe privately owned rights. Reference herein to any specific commercial product, process, or service by trade name, trademark, manufacturer, or otherwise does not necessarily constitute or imply its endorsement, recommendation, or favoring by the United States government or any agency thereof. The views and opinions of authors expressed herein do not necessarily state or reflect those of the United States government or any agency thereof.

This report is available at no cost from the National Renewable Energy Laboratory (NREL) at www.nrel.gov/publications.

Available electronically at SciTech Connect http:/www.osti.gov/scitech

Available for a processing fee to U.S. Department of Energy and its contractors, in paper, from:

\author{
U.S. Department of Energy \\ Office of Scientific and Technical Information \\ P.O. Box 62 \\ Oak Ridge, TN 37831-0062 \\ OSTI http://www.osti.gov \\ Phone: 865.576.8401 \\ Fax: 865.576.5728 \\ Email: reports@osti.gov
}

Available for sale to the public, in paper, from:

\author{
U.S. Department of Commerce \\ National Technical Information Service \\ 5301 Shawnee Road \\ Alexandria, VA 22312 \\ NTIS http://www.ntis.gov \\ Phone: 800.553 .6847 or 703.605 .6000 \\ Fax: 703.605.6900 \\ Email: orders@ntis.gov
}




\section{Table of Contents}

Acknowledgments …................................................................................................................... iv

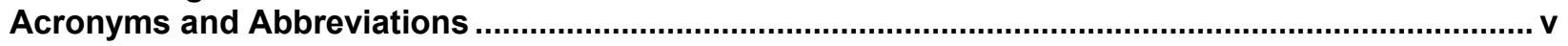

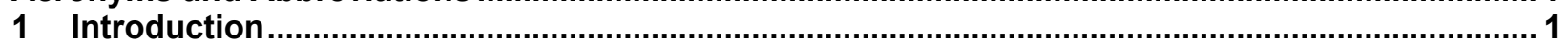

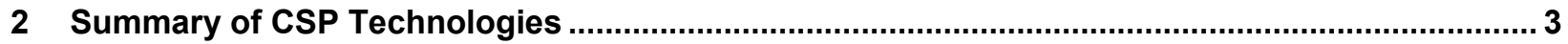

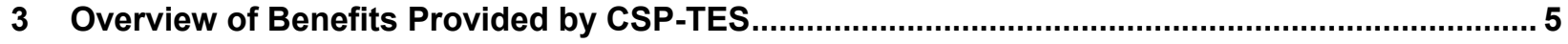

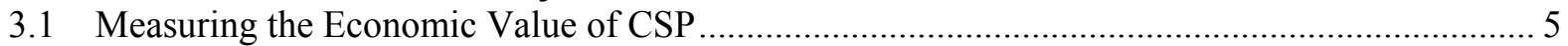

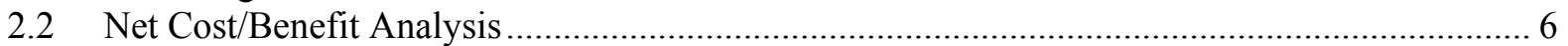

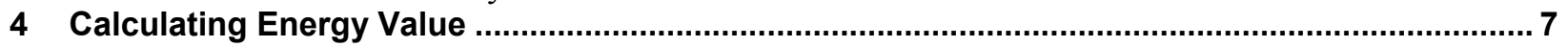

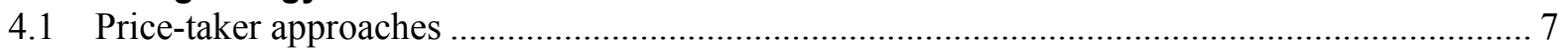

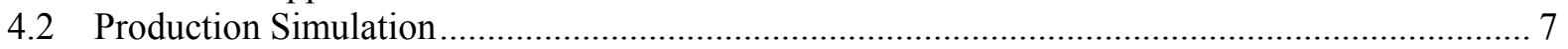

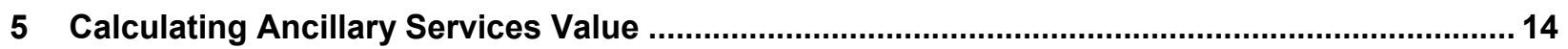

5.1 Analyzing the Value of CSP Providing Operating Reserves .............................................. 15

5.2 Analyzing the Impact of VG on Reserve Requirements ..................................................... 17

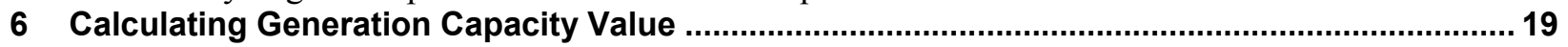

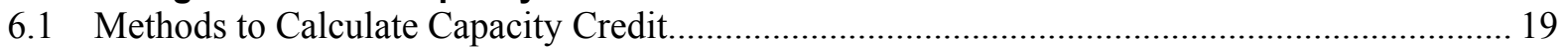

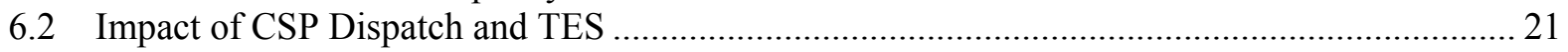

6.3 Translating Capacity Credit to Avoided Cost of New Capacity ….......................................... 22

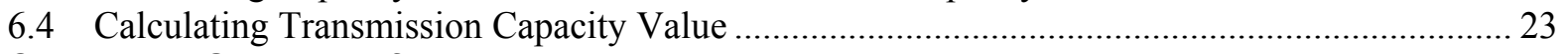

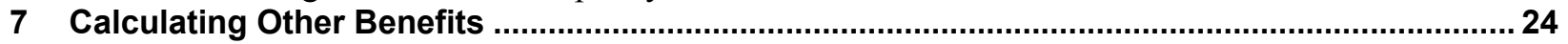

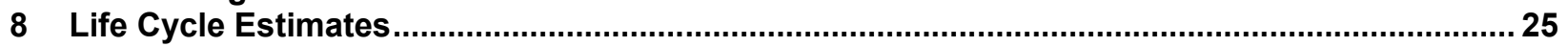

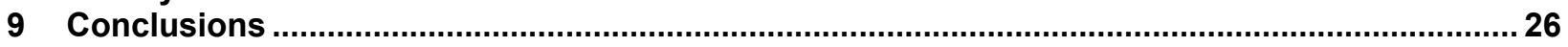

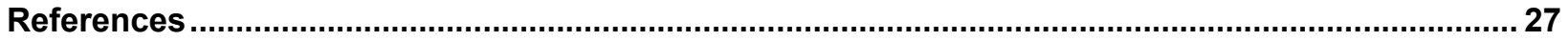

\section{List of Tables}

Table 1. Reserves That can Potentially be Provided by CSP ...................................................... 14

\section{List of Figures}

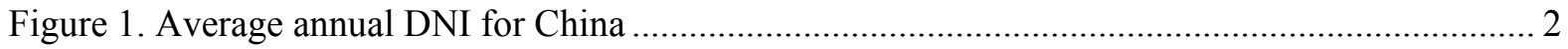

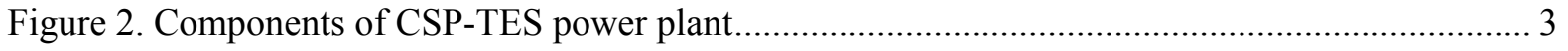

Figure 3. Impact of the SM on the energy flow of a CSP plant ....................................................... 4

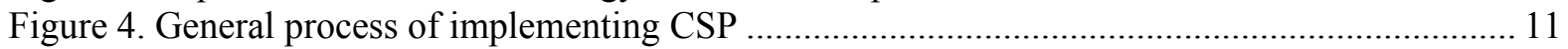

Figure 5. The flow of energy through a trough CSP plant with TES in PLEXOS ............................. 12

Figure 6. Graphical representation of ELCC calculations............................................................ 21 


\section{Acknowledgments}

This report was funded under the U.S. China Renewable Energy Partnership through the U.S. Department of Energy's Office of Energy Efficiency and Renewable Energy's International Team. The authors would like to thank the U.S. China Renewable Energy Partnership team for the opportunity to collaborate on the scoping and development of this study. For their review and comments, the authors would like to thank Aaron Bloom, Mark Mehos, and Kendra Palmer. Any errors or omissions are solely the responsibility of the authors. 


\section{Acronyms and Abbreviations}

AGC

CGN

CSP

CSP-TES

DNI

ELCC

GW

GWh

HVDC

IRENA

$\mathrm{kW}$

$\mathrm{kWh}$

LCOE

LMP

LOLE

LOLP

MW

MWh

NDRC

NEA

NERC

NREL

O\&M

PCM

PV

SAM

SERC

SM

TES

TW

TWh

VG automatic generation control

China General Nuclear Power Group

concentrating solar power

concentrating solar power with thermal energy storage

direct normal irradiance

effective load-carrying capacity

gigawatt

gigawatt-hour

high-voltage direct current

The International Renewable Energy Agency

kilowatt

kilowatt-hour

levelized cost of energy

locational marginal price

loss-of-load expectation

loss-of-load probability

megawatt

megawatt-hour

National Development and Reform Commission (China)

National Energy Administration (China)

The North American Electric Reliability Corporation

National Renewable Energy Laboratory

operations and maintenance

production cost modeling

photovoltaics

System Advisor Model

State Electricity Regulatory Commission (China)

solar multiple

thermal energy storage

terawatt

terawatt-hour

variable generation 


\section{Abstract}

Concentrating solar power with thermal energy storage (CSP-TES) provides multiple quantifiable benefits compared to CSP without storage or to solar photovoltaic (PV) technology, including higher energy value, ancillary services value, and capacity value. This report describes modeling approaches to quantifying these benefits that have emerged through state-level policymaking in the United States as well as the potential applicability of these methods in China. The technical potential for CSP-TES in China is significant, but deployment has not yet achieved the targets established by the Chinese government. According to the 12th Five Year Plan for Renewable Energy (2011-2015), CSP was expected to reach $1 \mathrm{GW}$ by 2015 and $3 \mathrm{GW}$ by 2020 in China, yet as of December 2014, deployment totaled only 13.8 MW. One barrier to more rapid deployment is the lack of an incentive specific to CSP, such as a feed-in tariff. The 13th Five Year Plan for Solar Generation (2016-2020), which is under development, presents an opportunity to establish a feed-in tariff specific to CSP. This report, produced under the auspices of the U.S.-China Renewable Energy Partnership, aims to support the development of Chinese incentives that advance CSP deployment goals. 


\section{Introduction}

The first 10-MW phase of Supcon Solar's 50-MW concentrating solar power (CSP) plant, located in the city of Delingha in the midwestern province of Qinghai, became China's first gridconnected CSP project in July 2013 (Xinhua 2013). China's first large commercial-scale CSP project, the 50-MW phase of the China General Nuclear Power Group (CGN) Delingha project, began construction in July 2014 and will be built with seven-hour molten salt thermal storage (CGN 2014).

CSP is nascent in China compared to the country's installed solar PV fleet of over 20 GW (NEA 2014). Yet, the country is aiming to achieve rapid growth in CSP capacity, announcing targets of $3 \mathrm{GW}$ by 2020. A large portion of China is endowed with high-quality solar resource favorable for CSP generation - specifically, direct normal irradiance (DNI) (see Figure 1). Areas favorable for CSP (DNI $\geq 5 \mathrm{kWh} / \mathrm{m} 2$-day, gradient $<3$ percent) could support about $16,000 \mathrm{GW}$ in installed capacity, which could generate as much as $42,000 \mathrm{TWh}$ per year (Li et al. 2009). The Asian Development Bank estimates that it is feasible for CSP to provide up to 15 percent of China's electricity by 2040 if the government proactively supports the industry (Servert 2012). In addition, CSP is a technology of interest due to its dispatchability (when deployed with thermal storage) and the potential for hybridization with coal or gas (Waldron 2014).

Relatively high capital cost compared to wind and PV, limited policy support, and remoteness have greatly constrained CSP deployment in China. While policy or fiscal tools-especially feed-in tariffs, tax rebates, and deductions - are commonly employed to support wind and PV markets in China, they have not yet been issued for CSP on a national level. In addition to spurring early capacity deployment, such measures allow the technologies to come down the cost curve and potentially give rise to a mature industry (Lewis and Wiser 2005). In 2013, for example, China established a series of policies including a feed-in tariff for solar PV to address overcapacity in the PV manufacturing sector. This led to a record $12 \mathrm{GW}$ of newly installed solar PV in China in 2013. Despite having a target for increased CSP deployment, the government so far has not decided on a feed-in tariff for CSP, announcing that evaluation would be carried out after the plants have been completed to ascertain the real cost of production for CSP (NEA 2014).

The cost disparity between CSP and solar PV has seen limited CSP development in China (Xu 2014). Chinese industry experts estimate that the current cost of production for CSP averages $\$ 0.22 / \mathrm{kWh}$ (Zhu 2014) compared to $\$ 0.10-\$ 0.12 / \mathrm{kWh}$ for PV (Li and Cao 2014). This significant differential reinforces the importance of accurately valuing the power system characteristics of CSP with thermal energy storage (CSP-TES). CSP-TES provides multiple value streams: energy value, ancillary service value, capacity value, and others. Estimated accurately, the relative value of CSP-TES becomes more attractive. 


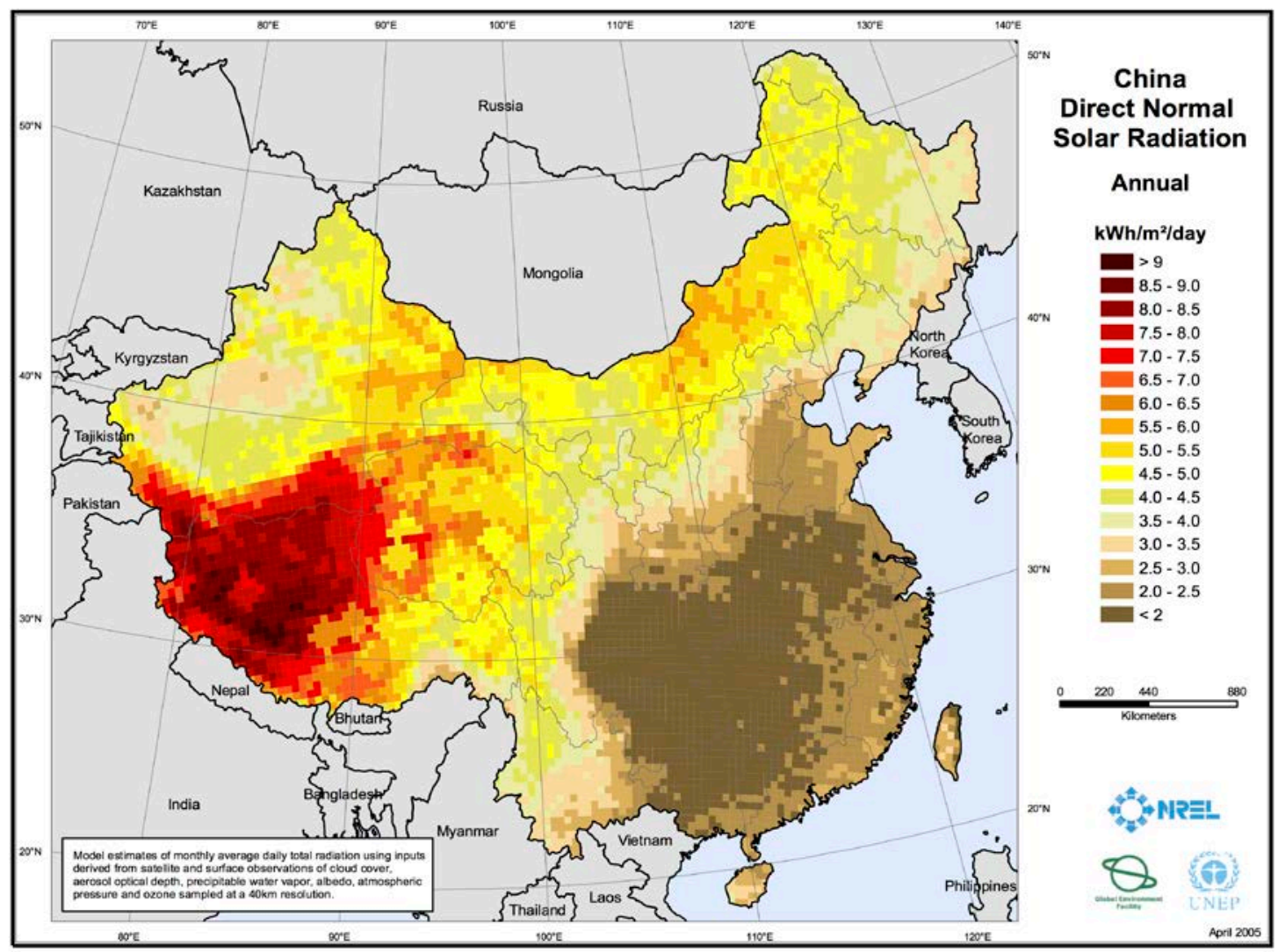

Figure 1. Average annual DNI for China

This report presents emerging valuation methods from the United States that may assist policy, planning, and coordination of CSP-TES plants in China. Following an overview of the basic structure of CSP plants with TES, and a brief overview of potential benefits provided by CSP, the report is divided into five parts to introduce the methods to perform each task and the amount/type of data required:

1. Energy value is calculated by using production cost modeling (PCM) to simulate the optimal system-wide dispatch of CSP-TES. Energy value of CSP-TES is derived by modeling both a base case and a case with an added CSP-TES generator to arrive at an estimate of avoided fuel costs.

2. Ancillary services value is calculated by using PCM to evaluate the ability and value of CSP to provide various operating reserves.

3. Capacity value, or the amount of conventional capacity that can be offset by CSP-TES, is calculated by measuring the loss of load probability, or the effective load-carrying capacity in a system with and without CSP-TES.

4. Transmission capacity value is calculated by estimating the efficiencies gained in transmission capacity when a CSP plant shares transmission with other sources of generations.

5. Other benefits are discussed briefly - for example, the role of CSP in providing a hedge against fuel price volatility. 


\section{Summary of CSP Technologies}

Multiple CSP-TES technologies are being deployed internationally. Figure 2 shows a generic CSP-TES configuration consisting of a solar collector, receiver, thermal storage, and power block. The reflective solar collectors (typically heliostats or parabolic troughs) direct solar radiation to a receiver, transferring this energy to a heat transfer fluid. The heated fluid is sent to the power block, which converts thermal energy to electricity. If CSP is deployed with TES, the thermal energy can be stored for conversion to electricity at a later time. CSP-TES systems can either have direct or indirect storage. For direct storage configurations, the storage medium is the same as the heat transfer fluid. Indirect storage configurations use an intermediate heat exchanger to transfer thermal energy from the heat transfer fluid to the storage medium. In combination with the solar resource, the relative sizing of these three components (the solar field, storage tank, and power block) determine the plant's capacity factor, which is the ratio of the actual output of the plant with respect to the maximum possible output if it operated continuously at its rated capacity. A smaller solar field results in reduced thermal energy delivered to the power block and a lower capacity factor. An undersized power block relative to the solar field, in the absence of sufficient thermal storage, can result in wasted energy during hours of high solar irradiance.

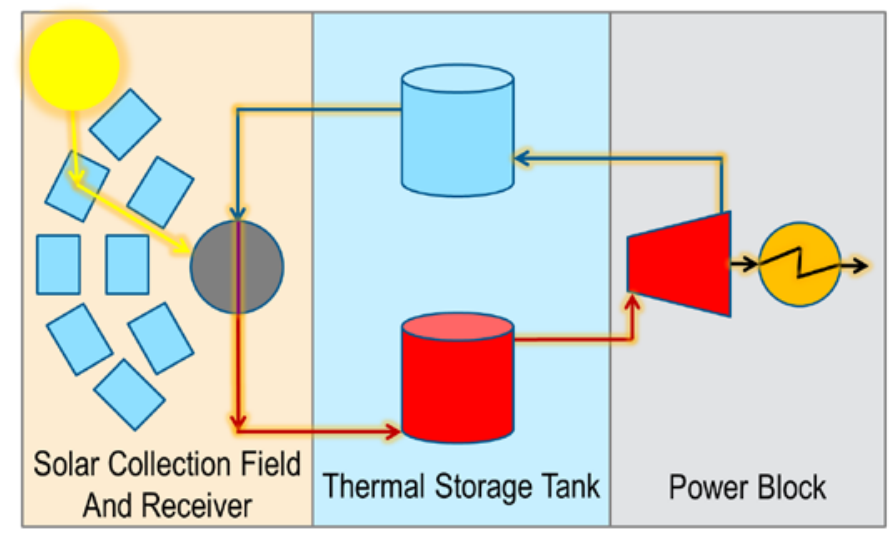

Figure 2. Components of CSP-TES power plant

A design parameter called the solar multiple (SM) normalizes the size of the solar field with respect to the power block. An SM of 1 is sized to provide the power block with enough energy to operate at its rated capacity under reference solar conditions. A larger SM implies a larger solar collector area. For instance, Figure 3 depicts a CSP plant with a power block rating of 300 MW and a solar multiple of 2. Any electrical energy delivered from the solar field which exceeds the maximum thermal rating of the power block rating must be stored or dumped (for systems without storage). As the diagram indicates, excess energy from an oversized solar field (an SM greater than one, in yellow) can be sent to thermal storage and subsequently delivered to the power block, which results in a higher plant capacity factor. 
Energy stored or sent to power block Energy that must be stored

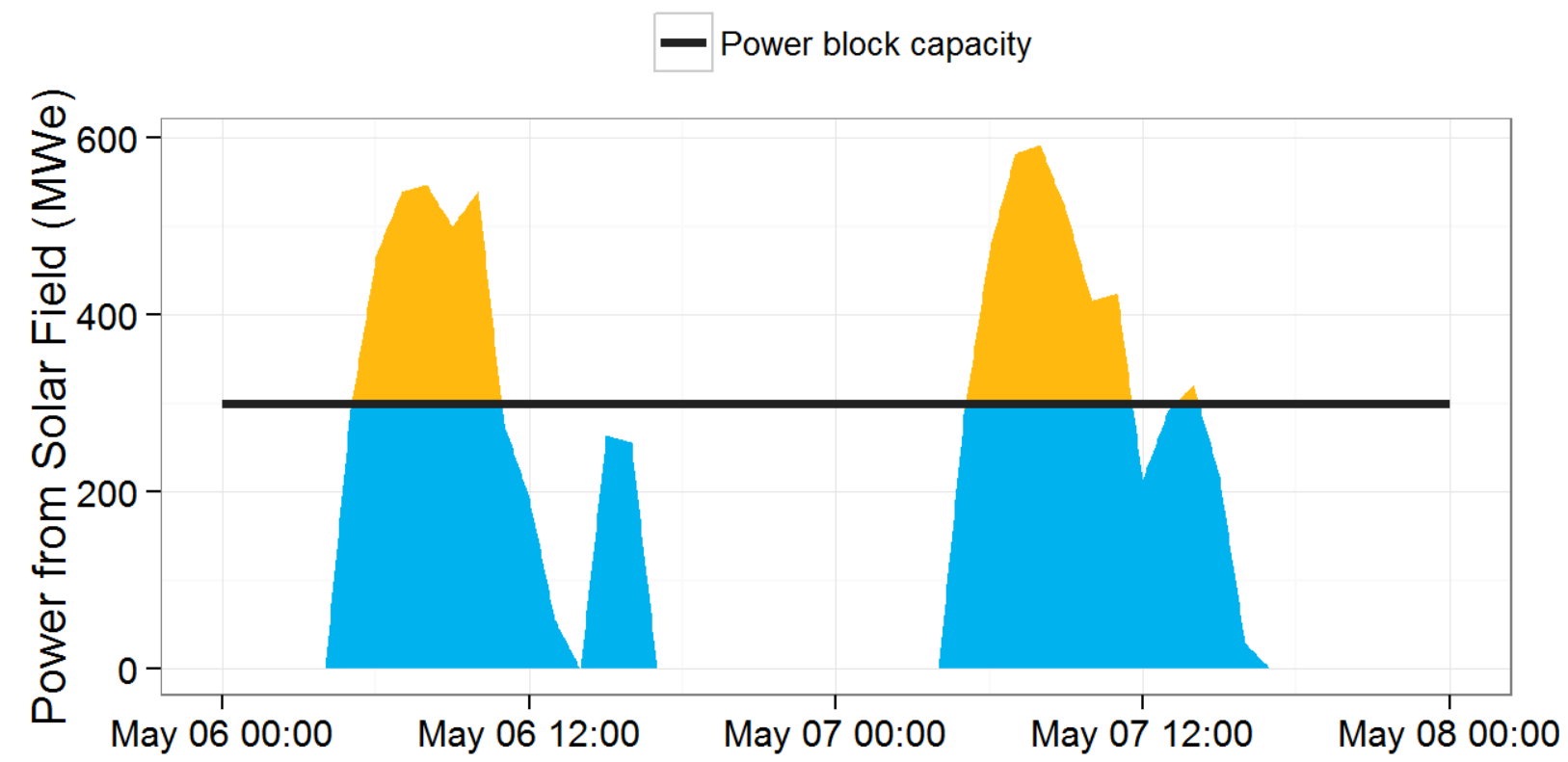

Figure 3. Impact of the SM on the energy flow of a CSP plant

CSP can be deployed with or without TES. CSP without TES is non-dispatchable, with a variable and uncertain output similar to PV. The decreasing costs of PV has made CSP without TES less attractive, and growing interest in the value of flexible generation has increased focus on CSP-TES. As a result, this discussion considers only CSP-TES. 


\section{Overview of Benefits Provided by CSP-TES}

CSP-TES provides multiple benefits which can be divided into two major categories: avoided variable costs and avoided fixed costs. These value streams are often calculated separately using different modeling approaches.

Variable costs include fuel, variable operations and maintenance (O\&M), environmental costs, and certain costs associated with ancillary services. Value is derived primarily from the ability of CSP-TES to reduce the costs of fossil fuels used for generation. This can also produce environmental benefits from reduction in air emissions but could also include avoided (or increased) water use. CSP can also avoid a variety of fixed costs associated with new generation that may be avoided by CSP-TES deployment as well as extra transmission, or decreased transmission, compared to VG sources. Some categories of benefits such as ancillary services can consist of both variable costs associated with changes in operation of the power system and fixed costs. Ancillary services include providing voltage control (including reactive power), and operating reserves such as frequency regulation, contingency, and flexibility reserves. CSP- TES can be operated at part-load to provide reserves (a net benefit) and can be compared to nondispatchable resources that can increase the variability and uncertainty of the system net-load.

\subsection{Measuring the Economic Value of CSP}

Multiple tools and approaches are typically required to measure the economic value of CSP-TES. Evaluating the categories with separate tools and summing the values might result in double counting of benefits that could be present in multiple categories, so care must be taken to isolate the individual value components.

The net value of CSP-TES can be expressed using a number of performance metrics, including the following:

1 Annual or life cycle total value (\$)

2 Annual or life cycle value per unit of installed capacity $(\$ / \mathrm{kW})$

3 Annual or life cycle value per unit of generated electricity ( $\$ / \mathrm{MWh}$ or $\phi / \mathrm{kWh}$ ).

Several previous studies use the third metric, expressing value of CSP-TES in terms of its production to facilitate comparison with other technologies. While relatively easy to express, calculating this value in terms of a single metric is challenging. Certain benefits, such as energy production from CSP, are easy to express on a cents-per-kWh basis. However, certain other benefits, such as avoided investments in capital equipment, must be translated into variable benefits, often by "annualizing" them using standard financing mechanisms (Short et al. 1995). As a result, estimating the value of CSP requires a substantial number of financial assumptions in addition to technical parameters. Furthermore, estimating value over a life cycle or over multiple years introduces additional challenges, such as forecasting fuel prices and estimating how the grid may evolve over time.

The following sections describe approaches that can be used to evaluate each value category separately. Each section first provides additional technical details about the source of value. It then discusses the approaches and tools needed to estimate the cost or benefit of CSP at any 
single point in time, followed by a discussion of how the life cycle value of CSP can be estimated considering fuel price variations, evolving grid mixes, and CSP-penetration impacts.

\subsection{Net Cost/Benefit Analysis}

It is important to note that the methods discussed in this paper address only the value provided by CSP and do not consider the costs. The costs of CSP can be calculated and compared to the net value considering three major components:

1. Plant capital cost

2. Transmission cost

3. Fixed and variable $O \& M$.

These costs can be assessed using the same metrics as discussed in Section 3.1, with levelized cost of energy (LCOE) being among the most common performance metrics used for new generation. For additional discussion of the cost of CSP and LCOE calculation, see IRENA (2012). 


\section{Calculating Energy Value}

The energy value of CSP results from its ability to displace conventional fossil resources and their associated costs and emissions. With sufficient TES, CSP output can be dispatched to provide energy during the hours of highest system value, typically during peak periods of the day.

There are two general approaches (discussed in the following sections) to simulating the optimal dispatch of CSP-TES and estimating which plants, and corresponding generation costs, will be displaced by CSP-TES generation.

\subsection{Price-taker approaches}

Price-taker approaches are commonly used to estimate the market value of new technologies in locations with wholesale markets. The price-taker approach applied to CSP would use a CSP dispatch model, where CSP is optimized to maximize profit against system historic locational marginal prices (LMPs) or system marginal energy prices.

Extensive discussion of price-taker approaches to simulating the value of CSP is provided by Sioshansi and Denholm (2013), Madaeni et al. (2012), Brand et al. (2012), and Usaola (2011). These approaches have the advantage of being relatively easy to implement and require limited data. They are useful in providing a preliminary estimate of potential revenues of a plant in a market-based power system. However, price-taker models depend on historic data and cannot evaluate the impact of grid mix, fuel prices, or other changes that could occur in the future. ${ }^{1}$ Because of these and other significant limitations, these approaches are not discussed further.

\subsection{Production Simulation}

Production simulation approaches use grid-simulation tools that model the operation of the entire generation fleet. These tools have a number of names including "production cost" and "securityconstrained unit commitment and economic dispatch" models. We use the term PCM to represent the class of models that simulate the chronological operation of the power grid, determining which power plants to commit and dispatch during each interval of time. ${ }^{2}$

Currently, China's electricity system does not use economic dispatch, but it has been attempting to transition away from a central planning model. In China, wholesale generation prices are assigned to power plants based on production costs and annual operating hours for different types of plants (Zhang 2009). Power was not dispatched in order of lowest marginal cost, but rather at assigned operating hours that are roughly the same across each type of generation (Gao and Li 2010). In 2007, the government launched reform efforts in five provinces to encourage "efficient dispatch" in which renewable generation, nuclear, and cogeneration units are prioritized before natural gas and gasified coal, coal generation, and oil-fired units (NDRC 2007). In addition, China's State Electricity Regulatory Commission (SERC) promulgated measures that require grid companies to purchase all renewable energy subject to grid security

\footnotetext{
${ }^{1}$ Alternatively marginal price data can be simulated using a PCM, as discussed in Section 3.2.

${ }^{2}$ As discussed below, we differentiate detailed chronological models such as PCMs from capacity-expansion models which do not perform chronological simulations or which simulate only a subset of hours.
} 
constraints, regardless of dispatch system (SERC 2007). China has had several failed attempts in piloting bid-based wholesale power markets in several regions. In 1999-2001, Zhejiang Province tested this model after the demand drop following the Asian financial crisis, but as soon as the economy recovered, electricity was in tight demand again, and the bidding system could no longer continue. A bid-based wholesale power market was also tested in Guangdong in 2003. In 2004, the newly established SERC chose the northeast region, where power supply was relatively sufficient, for switching to a competitive bidding process. But this reform effort was soon terminated after heavy lobbying from the grid company and large utilities (Zhang 2013; Wang 2012). In August 2014, the State Council ordered research on using a bid-based system in Heilongjiang and Jilin provinces (State Council 2014). Most recently, Opinions on Further Deepening the Electric Power System Institution Reform was released in March 2015. This marks another push in the efforts to transition away from centrally-planned power system in China.

PCMs are useful for planning only in systems that use least-cost economic dispatch. In the absence of that, China may still use it to estimate the value a generator theoretical can provide. PCMs select the least-cost mix of generators needed to meet load while maintaining adequate reserves to meet contingency events and other reserve requirements. Such models typically simulate the grid for 1 year of operation in 8,760 1-hour time steps. ${ }^{3}$ PCMs calculate the total cost of system operation, including cost of fuel and O\&M, resulting from providing both energy and ancillary services which are co-optimized to minimize overall production cost. To model the grid realistically, these tools require extensive generator databases and include transmission constraints and other elements to capture the challenges of reliably operating the electric grid.

We distinguish a PCM that performs a more or less complete chronological grid simulation from capacity-expansion models that often include some limited dispatch capabilities. Capacityexpansion models are often used to generate a least-cost generation mix as part of integrated resource plans. These models can also be used to evaluate different generator portfolios and have been used to estimate the value of CSP-TES (Mills and Wiser 2012b). In theory, a capacityexpansion model could be used to evaluate the energy value of CSP, but most models do not include the level of detail of a PCM (including simulation of transmission, reserve requirements, and system-wide dispatch of the entire generation fleet for a period of one year in hourly or subhourly time steps.) Computational complexity has historically prevented capacity-expansion models from including complete chronological dispatch. However, as computational resources evolve, it may be possible for capacity-expansion models to capture many of the individual value components and become the primary evaluation tool for CSP-TES.

\subsubsection{Estimating Energy Value with PCM}

Calculating the energy value of CSP-TES with a PCM can utilize a difference-based approach. In this approach, two runs of the PCM are made: a base case, and then a case that includes the added generator (in this case, the additional CSP-TES plant). The run with added CSP will have a lower production cost because the simulation requires less fossil-fuel generation. Once the

\footnotetext{
${ }^{3}$ There has recently been greater emphasis on sub-hourly simulation, particularly for high-penetration wind and solar integration studies. However, not all PCMs have this capability, and relatively few studies of CSP have been completed to date that perform less than one-hour simulations (Lew et al. 2013).
} 
second run is complete, the differences are calculated, producing a net variable system value of CSP for one year. PCMs track operation at the plant level, so the analysis can determine precisely which plants change operation between the two cases. Separate cost categories are tracked including fuel, O\&M, starts, and emissions. These can be added to derive a value per $\mathrm{kWh}$ of CSP during any time interval of the simulation. The primary challenge in this approach is modeling the dispatchability of the CSP-TES plant.

\subsubsection{Modeling CSP in a PCM}

PCMs simulate the operation of each power plant using high-level thermodynamic characteristics that include heat rate (efficiency) as a function of load, start-up energy requirements, ramp rates, and start-up times. However, they do not include detailed thermodynamics characteristics of the components unique to a CSP plant, including the solar field, heat collection, or transfer systems and receiver. These complex processes are not included in commercial PCMs, so an intermediate modeling step is required to accurately model the dispatchability of CSP-TES. ${ }^{4}$ One approach, used by NREL (Denholm and Hummon 2012), uses a detailed CSP thermal model as an intermediate step in modeling CSP dispatch. The entire process is illustrated in Figure 4.

The modeling process begins with meteorological data for the same location as the CSP site to be simulated. These data should also be correlated to the weather year of the production simulation. There are various sources of meteorological data. In the United States, the National Solar Radiation Data Base provides hourly meteorological data for from 1961 to 2010, including modeled solar data derived from satellite imagery (Wilcox 2012). Commercial vendors also provide various levels of hourly and sub-hourly meteorological data. Critical parameters include DNI with secondary factors such as wind speed and humidity.

Once appropriate weather data are obtained, the next step is to create a flow of energy that can be dispatched in the PCM. The primary dispatch decision associated with CSP is whether to directly use the thermal energy produced from the solar field to generate electricity, store the energy in each time interval, or release energy from storage. As a result, the PCM must have some capability of modeling storage. Each PCM is different and treats energy storage differently. However, most PCMs have models that allow hydro systems with limited energy capacity to be optimally dispatched which allows for a common approach to modeling CSP. In this approach, CSP is simulated as a hydro plant, with the inflow of solar thermal energy converted into a flow of electrical equivalent energy that can be dispatched by the PCM. Electrical equivalent energy from the CSP plant is modeled as water which can be dispatched or stored in the same manner as in conventional hydropower plants.

The creation of electrical equivalent energy requires a CSP thermal model, such as in the System Advisor Model (SAM) (Gilman et al. 2008; Gilman and Dobos 2012), which includes models for wet- and dry-cooled troughs and towers. The model converts hourly irradiance and other meteorological conditions into thermal energy and then models the flow of thermal energy through the various system components. The model can then convert the thermal energy into net

\footnotetext{
${ }^{4}$ This is similar to how wind turbines and PV systems cannot be modeled using only meteorological data - this requires pre-processing of wind speed and insolation data to produce electrical output.
} 
electrical generation output. Typically the thermal model includes efficiency as a function of load, power block start-up losses, etc. However, because these factors are an inherent part of the least-cost dispatch decision within a PCM, it is most accurate to have the CSP thermal model convert all thermal energy to electrical energy at the design-point efficiency of the CSP plant, then use the PCM to dispatch this energy, and account for part-load operation, start losses, etc.

In previous NREL analysis, the electrical equivalent energy profiles were created using SAM, where all parameters that are affected by plant dispatch were moved out of SAM and into the PCM framework. This is accomplished by setting the CSP SM parameter (see Section 2) to 1; a larger SM and storage was implemented in the PCM as described in Section 3.2.3. In addition, the minimum generation levels and start-up energy requirements in SAM were set to zero and accounted for in the PCM. Parasitics were removed from the gross CSP generation to derive a net hourly generation. Operational parasitics calculated by SAM were subtracted from the electrical profile in a manner similar to other thermal power stations. There may also be constant parasitic loads (e.g., associated with fluid pumps) that occur even when the plant is not operating. This means that the CSP plant will draw a small amount of energy from the grid and incur a small associated cost. This can be simulated be adding a small constant load in the PCM simulations.

The product of the SAM simulation is raw electrical energy output, which is then used as an input into the PCM hydro algorithm. In each simulation time step, the model can send the electrical energy from the SAM simulations directly to the grid via a simulated power block, to storage, or a combination of both. The model can also choose to draw energy from storage. The simulated power block includes the essential parameters of the CSP power block, including startup energy, minimum generation level, and ramp-rate constraints. The model can include start-up losses in the dispatch decision by assuming a certain amount of energy is lost in the start-up process. Other considerations, such as start time, start cost, ramp rate, and minimum run time associated with the power block can also be added similar to conventional generators.

In CSP plants that use indirect storage, the additional efficiency losses in the storage process are also simulated. Depending on the level of detail, a single loss parameter can be used, representing both the efficiency losses in the heat exchangers and the longer-term decay losses. ${ }^{5}$ Separate loss parameters can be used, as some hydro models include decay loss parameters (representing evaporative losses or seepage in hydro storage). Constant parasitics can also be added by placing a constant load on the same bus as the CSP plant.

\footnotetext{
${ }^{5}$ Longer-term decay losses are relatively small and each new parameter in the model introduces complexity, which increases run time.
} 


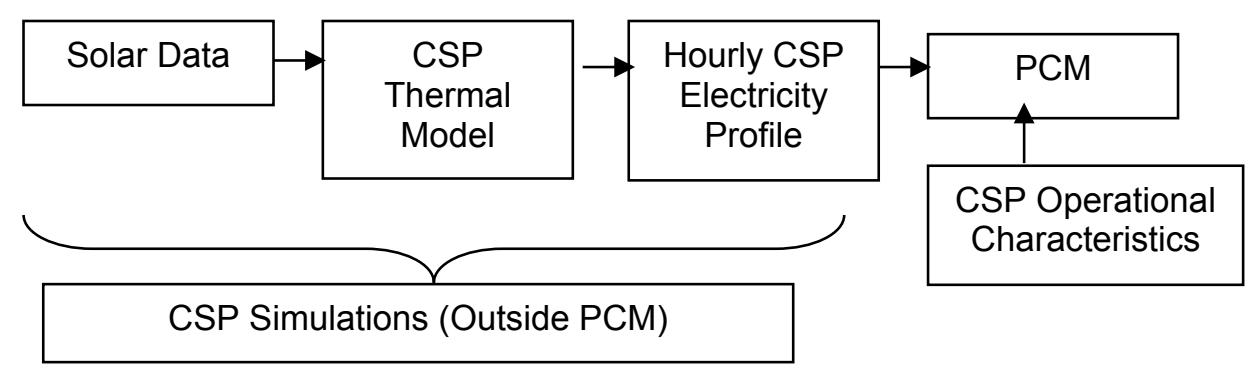

Figure 4. General process of implementing CSP

\subsubsection{Modeling SM and Storage Capacity}

Modeling CSP is complicated by the concept of SM, which is a measure of the relative size of the solar field and power block, and is an important factor in determining a plant's capacity factor and effective use of solar radiation. The SM normalizes the size of the solar field in terms of the power block size. For additional discussion of SM, see Jorgenson et al. (2013) and Izquierdo et al. (2010). A solar field with an SM of 1.0 is sized to provide sufficient energy to operate the power block at its rated capacity under reference conditions. The collector area of a solar field with a higher or lower SM will be scaled based on the solar field with a multiple of one (i.e., a field with a SM of 2.0 will cover roughly twice the collector area of a field with a SM of 1.0). A SM of 2.0 or greater is common in plants with storage, and the solar field with this SM will deliver twice the energy that can actually be used by the power block under reference conditions, meaning excess energy must be stored.

An SM can be simulated in a PCM by scaling the power block to some fraction of the maximum output of the solar field. For example, an SM of 2.0 can be simulated by setting the maximum size of the power block to $50 \%$ of the maximum output from the CSP simulations. The general implementation is illustrated in Figure 5, representing a 200-MW CSP plant with an SM of 2.0 and 6 hours of storage.

Figure 5 also shows the storage capacity, typically measured by hours of capacity at full output of the plant. This would be set in the hydro storage capacity, and in this example is equal to 1.2 GWh (200 MW multiplied by 6 hours). 


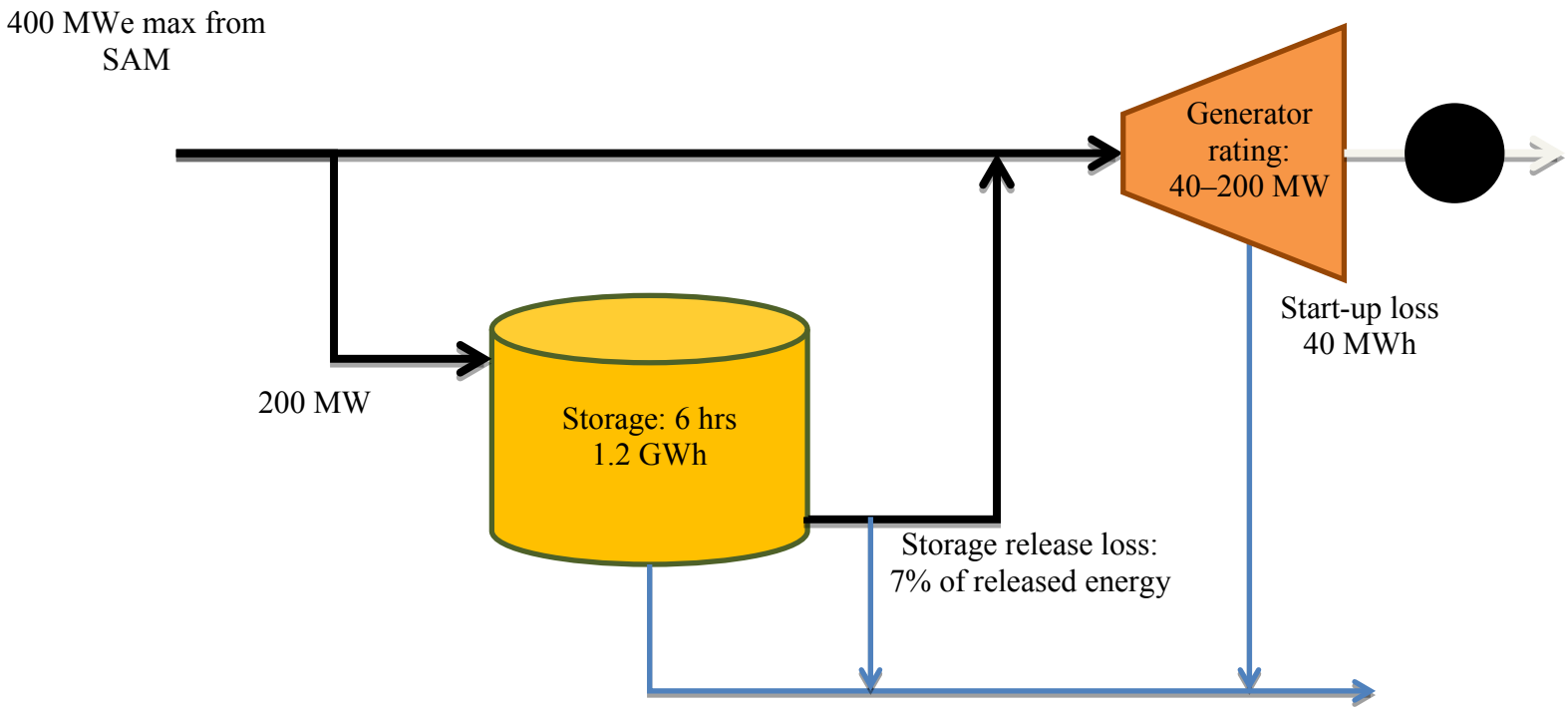

Figure 5. The flow of energy through a trough CSP plant with indirect TES in PLEXOS

\subsubsection{Other Data Requirements}

PCMs require a large amount of data such as performance data for each generator in the simulated area including heat rate as a function of load, start time, minimum up and down times, start costs, ramp rates, variable O\&M costs, and ability to provide ancillary services. Because system operation depends heavily on transmission capacity, PCMs also typically represent the transmission network and thus require extensive data sets. If the analysis is for a future year, the database must consider the addition or retirement of power plants as well as transmission additions.

PCMs typically require a full year of time-synchronized load, solar, and wind data. A common approach is to pick a historic year for which all data are available and to scale load profiles to incorporate future load growth. Using a single year of data does not account for how solar and weather conditions vary from average. There are limited options for addressing this issue. One is to pick a year that appears normal. Another is to perform simulations for multiple years and compare or average the results. Data collection, preparation, and processing are often the most difficult and time-consuming parts of running the multiple simulations required.

Because the difference-based approach requires two runs (a base case and an added-solar case), the level of CSP penetration must be determined. If the amount of CSP added to the PCM is very small, the impact of the CSP might be within the PCM's level of uncertainty and thus be unidentifiable. The minimum amount of CSP (or any other change) added to a PCM for the result to be "real" has not been precisely identified.

Additional data might be required to calculate reserve requirements based on short-term ramping events and limited ability to forecast the solar resource. These issues are discussed in Section 5.

\subsubsection{Avoided Emissions}

Both the quantity and potential monetary value of avoided emissions can be calculated by the PCM simulations. PCMs explicitly track fuel use at the plant level and can also track emissions. 
For $\mathrm{CO}_{2}$, this is very simple because of the direct relationship between fuel burned and emissions. For all thermal power-plant types, the emissions rate (for example, $1 \mathrm{~b} / \mathrm{kWh}$ ) is the $\mathrm{CO}_{2}$ content of the fuel (lb/Btu) multiplied by the avoided fuel consumption (Btu/kWh). ${ }^{6}$ PCMs can also calculate avoided emissions of other pollutants such as $\mathrm{NO}_{\mathrm{X}}$ and $\mathrm{SO}_{2}$, but their emissions rates depend on the presence of emissions controls as well as fuel type and heat rate, thus requiring generator-level emission rates for each pollutant.

Monetary values can be calculated using assumed emissions costs. These represent fees, taxes, or permit prices in a cap-and-trade regime. A reduction in emissions corresponds to a reduction in direct costs or the freeing up of permits, which can be sold to other generators. This could also include the variable cost of operating existing pollution-control equipment. In some cases, external or social costs can also be applied. These values can be calculated after the runs are complete; however, any direct (internal) costs incurred by the utility as part of their operation can also be used as part of the model objective function to minimize overall production cost.

Studies may consider environmental impacts other than air emissions using a variety of approaches. For example, if a variable cost of water consumption exists, the value of avoided water consumption can be calculated assuming the plant-level water consumption rate can be quantified and correlated to the generator type (Macknick et al. 2012).

\footnotetext{
${ }^{6}$ Unlike for $\mathrm{SO}_{2}$ and $\mathrm{NO}_{\mathrm{x}}$, the emissions rate for $\mathrm{CO}_{2}$ depends only on heat rate and fuel type because $\mathrm{CO}_{2}$ capture equipment has yet to be deployed in any significant quantity.
} 


\section{Calculating Ancillary Services Value}

Ancillary services represent a broad array of services that help system operators maintain a reliable grid with sufficient power quality. For this survey, we consider a subset of ancillary services that could be provided by CSP: operating reserves that can be provided by operating a CSP plant at part-load and varying output on multiple timescales.

Operating reserves address short-term supply/demand variability and plant outages. In the United States, these reserves are not uniformly defined, and the nomenclature used for various operating reserves varies significantly across market regions. For additional discussion of terms applied to various reserve products, see the North American Electric Reliability Corporation Glossary of Terms Used in Reliability Standards (NERC 2014) and Ela et al. (2011).

Table 1 provides examples of several operating reserves that are traditionally required at the transmission level and are typically provided by conventional generators.

Table 1. Reserves that can Potentially be Provided by CSP

\begin{tabular}{|l|l|}
\hline \multicolumn{1}{|c|}{ Operating Reserve Type } & \multicolumn{1}{c|}{ Description } \\
\hline Contingency reserve & $\begin{array}{l}\text { Reserves held to meet unplanned generation or } \\
\text { transmission outage }\end{array}$ \\
\hline Primary frequency response & $\begin{array}{l}\text { Reserves held to automatically respond to instantaneous } \\
\text { active power imbalance and stabilize system frequency }\end{array}$ \\
\hline $\begin{array}{l}\text { Frequency-regulation } \\
\text { reserves/Secondary frequency } \\
\text { response }\end{array}$ & $\begin{array}{l}\text { Reserves held to respond to small, random fluctuations } \\
\text { around normal load }\end{array}$ \\
\hline Flexibility reserves & $\begin{array}{l}\text { Reserves held to respond to variations in net-load on } \\
\text { timescales greater than those met by frequency regulation } \\
\text { and meet variations due to forecast error }\end{array}$ \\
\hline Non-spin/replacement/tertiary & $\begin{array}{l}\text { Replaces or supplements various spinning reserves } \\
\text { services }\end{array}$ \\
\hline
\end{tabular}

The costs associated with providing operating reserves result from changes to system operation needed to meet reserve requirements. These include the impact of operating generators at partload, more frequent starts, and other reductions in dispatch efficiency due to holding reserves. Hummon et al. (2013a) provide an extensive discussion of the origin of reserves costs. ${ }^{7}$

Under Chinese power regulations, ancillary services are separated into two categories: 1) unpaid services, including primary frequency regulation, basic peak regulation, and basic reactive power regulation, and 2) compensation for services, which includes automatic generation control (AGC), additional peak regulation reserves, additional reactive power regulation, and black start (SERC 2006). China is gradually building up its ancillary service trade mechanism. The BeijingTianjin-Tangshan grid was the first to establish such a mechanism in May 2009. Its main

\footnotetext{
${ }^{7}$ Changes in operating reserves could also change the fixed-cost components of a power system by requiring more or different types of generators. The impact of different reserve requirements on the optimal mix of generator types is not well understood.
} 
products are $\mathrm{AGC}$, reactive power regulation, peak regulation, and black start. By the end of 2012, the trading area covered a total of $49 \mathrm{GW}$ generators, and monthly trade has stabilized to around $\$ 7.3$ million, or 0.8 percent of the electricity price of the same period.

A fee is exacted from all generators based on the percentage and paid to the ancillary service providers. Currently, ancillary service trade exists in a large part of the country, and the total trade amount reached \$346.36 million in 2011 (Liu 2013). With increasing penetration of variable renewable generation such as wind and solar PV in China, there is an increasing need for improvement of ancillary service trading mechanisms and construction of ancillary service markets. According to the Opinions on Further Deepening the Electric Power System Institution Reform, released in March 2015, a new mechanism for ancillary service sharing will be established, through which the evaluation and compensation mechanism for generation companies will be improved.

In China, spinning reserve is commonly set to be no less than the maximum value of $5 \%$ of the grid peak load or the rated capacity of the single largest generator. With the commissioning of high-voltage direct current (HVDC) projects, as well as increasing penetration of variable renewables, the failure of HVDCs and the capacity of wind farm and PV power stations in the same integration areas are also considered in spinning reserve requirements. One extreme example is West Inner Mongolia, where there is large amount of wind power and daily spinning reserve averages to around $3 \mathrm{GW}$, which is 25 percent of the grid's daily load (Fu 2012). The requirements for spinning reserves with large amounts of renewable energy integration is currently being explored in China. (Hu et al. 2015; Xu et al. 2014)

The value of CSP associated with providing operating reserves is derived from two components. First, CSP can provide reserve services by operating a part-load in a manner similar to conventional hydro and thermal generators. Second, even if CSP does not provide reserves, the dispatchability of this resource may reduce reserve requirements compared to variable generation (VG) resources such as PV and wind, which may be an element of comparing different generation technologies.

As a result of these two factors, evaluating CSP providing ancillary services compared to VG resources requires two sets of calculations, as discussed in the following two sections. The first is simulating where CSP is allowed to provide reserves, and then calculating the value of these services. The second is calculating the impact of alternative generation resources to overall reserve requirements.

\subsection{Analyzing the Value of CSP Providing Operating Reserves}

The impact of CSP providing reserves can be evaluated in part using a difference-based approach with a PCM. The analysis would consist of performing two PCM runs. Commercial PCMs generally include the capability to "carry" one or more reserve products. ${ }^{8}$ This means they can, in theory, calculate the impact of part-load operation, increased starts, and increased O\&M

\footnotetext{
${ }^{8}$ PCMs carry reserves by enforcing a constraint that maintains a certain amount of spare operating capacity, which can increase output at a certain ramp rate. They typically do not actually simulate reserve deployments because of the much shorter timescales associated with reserve events.
} 
resulting from the provision of various operating reserves. The amount of reserves held by the model can vary in each simulation interval, so, for example, the regulation or flexibility reserves can vary as a function of load or net-load considering the impact of VG.

By operating at part-load, it is possible for CSP-TES plants to provide a variety of operating reserves including spinning contingency, regulation, and load-following reserves. While it may be possible for CSP to provide non-spinning/replacement reserves, these reserves often require extended operation and may not be well suited to limited energy resources such as CSP.

The quantity of reserves that can be provided by CSP depends on factors including operating range and ramp rate at the time scale of each reserve service. For "up" reserve services (reserve services which require an increase in generator output), the combined maximum provision at any interval is the plant-rated capacity minus its current operating point. The maximum for "down" reserve services (reserve services which require a decrease in generator output) is set by the minimum operating level of the plant. The reserve provision is also subject to the speed at which a generator can change its output level, also known as ramp rate.

The ability to provide reserves is constrained by the actual provision of real energy during any given time period. A plant providing regulation reserves is constantly increasing or decreasing output in response to a regulation signal. This means that at any given point, the plant is providing more or less energy than its scheduled energy output. As a limited energy resource, CSP cannot provide continuous up regulation services beyond what is being added to storage or what is held in storage during the "up" event. There are several approaches to simulating the provision of reserves with a limited energy storage device. A simplified approach used by NREL is to assume symmetric regulation operation in a manner similar to simulation of electricity storage devices (such as batteries) when providing regulation reserves. A conventional storage plant providing regulation reserves essentially operates at a zero output setpoint, and then provides up regulation by discharging or down regulation by charging. ${ }^{9}$ If regulation is a netzero energy service over a relatively short time period, limited energy storage devices should be able to provide continuous regulation service. A more detailed approach, which would allow for asymmetric provision of reserves is to account for the real energy that would be dispatched by a plant providing up (or down) regulation. This requires an assumption about the amount of time the plant providing regulation actually spends providing energy above its normal dispatch point when providing up regulation (and below when providing down regulation). ${ }^{10}$

Additional considerations include the increased fuel use and O\&M costs associated with reserve provision. This is particularly notable for regulation reserves, where generators often offer a nonzero bid price for providing regulation services due to additional wear and tear and heat rate degradation associated with operating at a constantly changing setpoint.

\footnotetext{
${ }^{9}$ In reality, the setpoint would be a small constant charge (negative output) to compensate for round trip storage losses and any constant energy decay losses that will occur.

${ }^{10}$ This also requires accounting for the value of the energy provided when providing regulation.
} 


\subsection{Analyzing the Impact of VG on Reserve Requirements}

Another important consideration is the relative impact of different generation sources on reserve requirements. Regulation reserve is historically intended to meet short-term variation in demand. The added variability and uncertainty created by wind and solar can increase reserve requirements, so it is expected that, as VG penetration increases, regulation reserve requirements will also increase (Ela et al. 2011). Because CSP-TES is not as variable and uncertain, it is expected that it will not increase these reserve requirements. ${ }^{11}$

As a result, studies that compare the relative value of CSP to VG resources will need to adjust the reserve requirements. This requires calculating the reserves required due to added VG resources by evaluating the statistical variability of wind and PV to calculate the additional regulation and flexibility reserves required.

Wind and solar integration studies have also used a variety of tools to calculate the increase in reserve requirements (Lew et al. 2013; Ibanez et al. 2012; Etingov et al. 2012; Diao et al. 2011; Makarov et al. 2010). Estimating additional reserve requirements due to solar (and wind) is an area of ongoing study, and the actual need is not well established. New reserve products have yet to be uniformly defined and accepted. For example, some of the variability of solar and wind occurs on a timeframe longer than the traditional regulation product, so there have been proposals to create a new reserve product primarily to address the characteristics of VG. This product has not been uniformly defined or named, but "flexibility reserve" and "ramping reserve" are two of the more commonly applied terms (Xu and Tretheway 2012; Navid et al. 2011; Wang and Hobbs 2013).

Calculation of reserve requirements requires significant amounts of data. The following is a list of sub-hourly time profiles required by the NREL reserve method:

1. Actual and day-ahead forecasted demand

2. Actual and day-ahead forecasted wind power

3. Actual and day-ahead forecasted PV power

4. Clear-sky PV power (i.e., the expected power output from PV plants assuming an absence of clouds).

Generating these data sets requires corresponding meteorological data — both predicted and actual insolation on an hourly or sub-hourly timescale. Sub-hourly data and solar forecast data over large areas for multiple historic years are not widely available. Statistical methods can be used to "down-scale" hourly data sets to sub-hourly data sets for calculation of sub-hourly variability and also to produce synthetic "forecasts" from actual data (Hummon et al. 2013b).

The tools and methods discussed only evaluate the impact of VG on system operation and reserve requirements in timescales down to a few minutes. While the cost of holding reserves can

\footnotetext{
${ }^{11}$ Most studies typically assume wind and solar do not affect contingency reserve requirements, especially studies that assume these reserves are based on failure of discrete plant or transmission lines (single largest contingency). This is based on the assumption that no single solar or wind plant will be the single largest point of failure.
} 
be estimated, costs of actually deploying reserves are generally not considered in commercial PCMs. The more frequent use of regulating reserves associated with large-scale deployment of VG requires use of a new class of model, which simulates power system operation at the timescale of a few seconds, or the timeframe of automatic generation control (Ela et al. 2013). 


\section{Calculating Generation Capacity Value}

Production simulations only calculate the operational costs of an electricity system, typically only for a single year. CSP plants also provide capacity value, which is the ability to replace or defer capital investments in generation or transmission capacity.

Estimating the generation capacity value of CSP requires two steps. The first is to calculate the actual fraction of a CSP system's capacity that could reliably be used to offset conventional capacity. This value, also referred to as capacity credit, ${ }^{12}$ is typically measured either as a value (such as $\mathrm{kW}$ ) or percentage of nameplate rating. The second step is translating a capacity credit to a monetary value of reduced capacity needs.

\subsection{Methods to Calculate Capacity Credit}

There is considerable literature on methods to estimate generation capacity credit of VG resources (Mills and Wiser 2012b, Keane et al. 2011, Castro and Ferreira 2001), but this report will discuss two of the most common general approaches. The first is the use of capacity factor approximations, which examine the output of a generator during periods of highest net demand or highest loss-of-load probability (LOLP). These methods reflect that the capacity credit of a resource represents its ability to reliably meet load or reduce the need for conventional capacity. This can occur if CSP reduces the peak demand for electricity and thus reduces the need for peaking capacity. Capacity factor approximation approaches consider the output of a generator (capacity factor) over a subset of periods during which the system faces a high risk of an outage event. These periods generally correspond to periods of highest net-load. Thus, capacity factor approximation using net-load simply examines the average capacity factor of a resource over some set of the highest net-load hours. ${ }^{13}$ This approach requires only a spreadsheet with net-load data (equal to load minus generation contributions from wind and solar) and CSP generation data for the same subset of periods.

A somewhat more sophisticated approach (but still using a capacity factor approximation) replaces the highest-load hours with the riskiest hours, where risk is defined as the LOLP. LOLP is defined as the probability of a loss-of-load event in which the system load is greater than available generating capacity during a given period. It is calculated using the forced outage rates on all the power plants in the system, along with the load and expected wind and solar output. Conventional generator outages are typically modeled using an equivalent forced outage rate, which is the probability that a particular generator can experience a failure at any given time. In general, LOLP is highest when the net-load is highest, which justifies the highest net-load approach discussed previously and saves considerable analytic effort. There are several variations on this approach, including use of different periods (such as using the top 10 hours, top $1 \%$ of hours, or top $10 \%$ of hours) or adding additional weighting factors to the hours of

\footnotetext{
${ }^{12}$ Following Mills and Wiser (2012b), we use the term "capacity value" to refer to the economic value of PV in replacing conventional generation (measured in $\$$ or $\$(M W$ ) while we use "capacity credit" to refer to the amount of generation capacity avoided by CSP.

${ }^{13}$ See Madaeni et al. (2012) for a discussion of the impact of number of hours used.
} 
highest LOLP. ${ }^{14}$ This approach can still be used with a spreadsheet, but with a more detailed data requirement and additional calculations to generate the hourly LOLP.

The second class of methods includes reliability-based approaches which calculate the effective load-carrying capacity (ELCC) of an added generator. There are multiple approaches to calculating ELCC, with two of the more common being the iterative ELCC calculation and Garver's Method (NERC 2011). The ELCC of a generator is defined as the amount by which the system's load can increase when the generator is added to the system while maintaining the same system reliability. Reliability is measured by the LOLP and loss-of-load expectation (LOLE) (Amelin 2009). The LOLE is the sum of the LOLPs during a planning period-typically one year. LOLE gives the expected number of periods in which a loss-of-load event occurs. Power system planners aim for a certain LOLE target, such as 0.1 days/year or 0.1 events/year. ${ }^{15}$

The steps used in the iterative ELCC method is illustrated in Figure 6 and performed as follows:

1. For a given set of generators (excluding the new generator), calculate the base LOLE using loads, capacities, and outage rates (illustrated by the blue curve). Determine the system load that can be supplied while meeting the target reliability level (i.e., the intersection of the blue and red lines).

2. Add the new generator and recalculate LOLE for the load at which the base system meets the target reliability level. For the same load, the new LOLE value will be less than or equal to the LOLE of the base system.

3. Keeping the new generator in the system, add a constant load in each hour and recalculate LOLE. Additional load is added incrementally (moving along the green dotted curve) until the LOLE of the system with the added generator reaches the target reliability level. The green dotted curve represents the new reliability curve (i.e., the blue curve shifts to the right when the new generator is added).

4. The difference between the new and base load at a constant LOLE is the ELCC of the added generator (400 MW in this example).

\footnotetext{
${ }^{14}$ There are other approximation techniques with varying degrees of complexity. For more discussion, see Madaeni et al. (2012).

${ }^{15}$ For a discussion of reliability targets, see Pfeifenberger et al. (2013).
} 


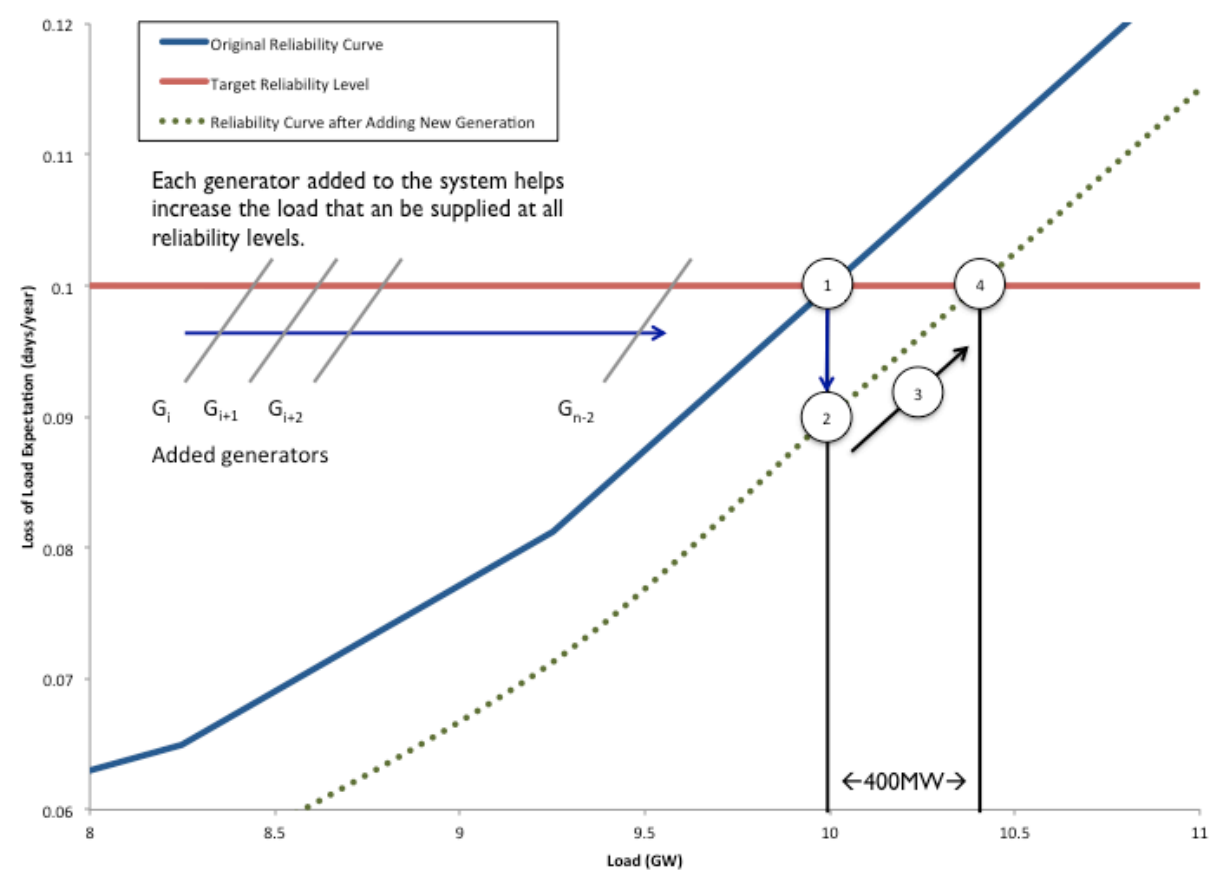

Figure 6. Graphical representation of ELCC calculations

This iterative ELCC calculation is computationally complex, and Garver's Method provides a less complicated method by avoiding the iterative LOLE calculations when the new generator is added to the system. It still requires calculating an initial set of LOLPs to create a "slope" of the risk function. This slope value is placed into a mathematical formula that relates ELCC to the additional generator. A number of commercially available tools can perform these calculations (Pfeifenberger et al. 2013), and several commercial PCMs include the ability to calculate PV ELCC (Xcel Energy 2013a).

There is a general consensus that ELCC methods are robust and widely accepted by the utility community. Previous studies have found that Garver's approximation and the full ELCC method often provide similar results for both wind (Keane et al. 2011) and PV (Madaeni et al. 2012). Overall, the tradeoff between the methods is often a function of data requirements, complexity, and transparency (Keane et al. 2011).

\subsection{Impact of CSP Dispatch and TES}

A distinct challenge of calculating capacity credit of CSP is the choice of output profiles and impact of stored energy availability. For pure VG sources such as wind and solar, the analysis just requires hourly profiles for the generators based on real or simulated meteorology. For completely dispatchable thermal plants, the primary driver behind capacity credit is outage rates or schedules, especially if fuel availability is certain. For CSP-TES, its dispatchability is much greater than VG sources, but less than for thermal plants with a secure source of fuel. As a result, additional analysis is needed to consider the interaction between CSP dispatch, storage capacity, and capacity value. 
There is no general consensus on the appropriate method to apply capacity credit calculations to CSP dispatch profiles generated by a PCM. One approach (Jorgenson et al. 2014) is to use the output profiles from the PCM combined with the amount of energy remaining in storage during each hour, following Tuohy and O'Malley (2011). This approach considers the actual output of the CSP-TES plant during periods of highest net-load and the availability of thermal energy to increase its output during those hours. For example, if the CSP-TES plant was dispatched below its full capacity during hours with high net-load, but has enough energy stored to increase its output, then it would receive a full capacity credit in this method. However, if the CSP-TES plant were forced to increase its generation over subsequent high-load hours, the available output could not exceed the thermal energy in reserve. That is, the calculation must reflect the energy limitations on the CSP-TES plant. This approach is then applied to the approximation methods described in Section 5.1. Other approaches have performed separate dispatch simulations (Madaeni et al. 2013) or developed dedicated tools (Sioshansi et al. 2014). Further analysis is likely needed to validate these approaches; however, most simulations have found high capacity values $(>90 \%)$ for systems with six hours or more of energy storage.

\subsection{Translating Capacity Credit to Avoided Cost of New Capacity}

Once the adjusted capacity credit calculation is performed, a monetary value per unit of installed CSP capacity can be calculated. This requires estimating the generator type avoided and the cost of this avoided generator.

One approach is to assume that CSP would replace a standard peaking or intermediate load generator such as a simple-cycle or combined-cycle gas turbine. In the United States, gas turbines are often used as a proxy resource for calculating the cost of new capacity. Once the type of generator is chosen, generator cost data can be used to generate an annualized avoided cost.

A slightly more complex approach employs the simplest form of capacity-expansion models that use screening or load-duration curves, traditionally used for planning generation capacity (Galloway et al. 1960). These curves use estimates of the likely capacity factor of generators serving different parts of the demand curve (baseload, intermediate, and peak) and estimate the optimal generation mix based on their fixed and variable costs. Such curves can be used to estimate the impact of the addition of CSP on the net-load curve and the likely generation mix effectively avoided by CSP. This approach has been widely used, but it cannot consider the impact of generator operational constraints or associated operational flexibility drivers that become critical with large penetrations of variable renewables (Shortt et al. 2013; Palmintier and Webster 2014). Adaptations to the screening curves have been proposed to help address these shortcomings (e.g., Batlle and Rodilla 2013).

The final approach uses a full capacity-expansion model to evaluate the generator type(s) avoided by CSP. Capacity-expansion models are commonly used by utilities to help determine the optimal mix of generators needed to meet load growth, generation retirement, or various other factors requiring new capacity. These tools are similar to PCMs in terms of data requirements, complexity, and costs. They can be used to evaluate the optimal generation mix with and without CSP to determine what would not have been built under various CSP scenarios (Sullivan et al. 2014). While complex, capacity-expansion models enable a more thorough treatment of the timing of generation assets. The monetary value of CSP capacity depends on a 
system actually needing additional capacity to provide an adequate planning reserve margin. Capacity-expansion models can simulate expected load growth and plant retirements and then assign appropriate capacity value to CSP, accounting for both the timing and type of required investment.

\subsection{Calculating Transmission Capacity Value}

CSP plants are generally sited in remote locations, typically requiring new transmission. As a result, CSP does not typically reduce transmission requirement compared to conventional generation, and transmission associated with CSP will typically result in a net cost, as opposed to a net benefit. However, because of its potentially higher capacity factor, CSP-TES can require less transmission per unit of energy delivered than remotely sited VG sources, and can potentially utilize spare transmission capacity built for VG resources. For example, Sioshansi and Denholm (2013) demonstrate how CSP and wind can share transmission built into areas with high quality wind and solar resources. Production simulation, which includes detailed power flows, can evaluate the needed transmission capacity and sharing of transmission capacity between various resources. 


\section{Calculating Other Benefits}

There are several other potential benefits of renewable resources that have been previously analyzed, including providing a fuel price hedge over long time horizons. The addition of CSP (or renewable energy more generally) to an electricity-generation portfolio may result in diversity-related benefits, which include providing a physical hedge against uncertain future fuel prices and insurance against the impact of higher future fuel prices or changes in emissions policy. Adding CSP to the generation mix could also reduce the demand for natural gas (and other fossil fuels), particularly in the long-term, which could reduce natural gas (and other fossil fuel) prices. 


\section{Life Cycle Estimates}

The methods described in the previous sections typically estimate the value of CSP for a limited period. For example, PCMs value the operational value over a period typically no more than one year. Considering the time horizon is important when estimating the value of CSP over many years or decades, particularly when comparing CSP to alternative generation technologies.

Life cycle valuation can be used to calculate the net present value of different resources. Avoided energy value will vary over time as driven by three factors: fuel prices, grid mixes, and CSP penetration. Life cycle value estimates include consideration of how each parameter will change over the project life.

Fuel prices typically use an escalation factor, similar to those generated for integrated resource plans. The other two factors, the grid mix and the CSP penetration, are closely related (Mills and Wiser 2012a). As CSP penetration increases, solar electricity begins to displace a different mix of generation; previous analysis has demonstrated displacement of lower-cost generation (Denholm et al. 2009). This, in turn, results in a different "least-cost" mix of generation, as capacity factors of conventional plants decrease and the system relies more on peaking-type generators. This equilibrium effect on the generation mix has been demonstrated (Mills and Wiser 2012a). However, considering alternative grid mixes requires generating new scenarios that project the impact of fuel prices and policy and economic drivers of grid evolution such as renewable portfolio standards, emission limits, and natural gas prices. 


\section{Conclusions}

CSP-TES is a unique source of electricity generation. It has much greater dispatachability than VG resources such as wind and solar PV; however, it is less dispatchable than conventional fossil resources. It also requires optimization of the limited energy available based on the variable and somewhat uncertain solar resource. As a result, it can be difficult to evaluate the benefits that CSP-TES provides to the grid. In this report, we survey the methods, data, and tools available for addressing this analytical challenge. We focus on the use of PCMs, and find that commercially available tools, with some modification, can provide reasonable estimates for how CSP can be dispatched.

With potentially large deployment of CSP in China and the government's push for power sector reform, adaption of these models in the Chinese context and evaluation of CSP economics will help policymakers establish incentive policies for CSP. These models can analyze the role of CSP in alleviating solar PV generation curtailment in northwest China, as well as its role in future high penetration renewable energy systems. Future work is recommended in these areas. 


\section{References}

Amelin, M. (2009). "Comparison of Capacity Credit Calculation Methods for Conventional Power Plants and Wind Power.” IEEE Transactions on Power Systems 24:2.

Batlle, C.; Rodilla, P. (2013). "An Enhanced Screening Curves Method for Considering Thermal Cycling Operation Costs in Generation Expansion Planning." IEEE Transactions on Power Systems 28 (4); 3683-3691.

Brand, B.; Stambouli, A.B.; Zejli, D. (2012). "The value of dispatchability of CSP plants in the electricity systems of Morocco and Algeria." Energy Policy 47; 321-331.

California Independent System Operator (CAISO). (2011). "Track I Direct Testimony of Mark Rothleder on Behalf of the California Independent System Operator Corporation (Corrected)." Before the Public Utilities Commission of the State of California, Order Instituting Rulemaking to Integrate and Refine Procurement Policies and Consider Long-Term Procurement Plans, Rulemaking 10-05-006.

CAISO. (2012). 2011 Annual Report on Market Issues and Performance. Folsom, CA: CAISO.

Castro, R. M., \& Ferreira, L. A. F. (2001). A comparison between chronological and probabilistic methods to estimate wind power capacity credit. Power Systems, IEEE Transactions on, 16(4), 904-909.

China General Nuclear Power Group (CGN). (2014). “China’s First Large Scale Commercial Concentrating Solar Power Plant Breaks Ground in Qinghai." CGN. Accessed December 2014: http://www.cgnpc.com.cn/n1302/n1303/c671831/content.html.

Denholm, P.; Wan, Y.; Hummon, M.; Mehos, M. (2013). Analysis of Concentrating Solar Power with Thermal Energy Storage in a California 33\% Renewable Scenario. NREL/TP-6A20-58186. Golden, CO: National Renewable Energy Laboratory.

Denholm, P.; Hummon, M. (2012). Simulating the Value of Concentrating Solar Power with Thermal Energy Storage in a Commercial Production Cost Model. NREL/TP-6A20-56731. Golden, CO: National Renewable Energy Laboratory.

Denholm, P.; Margolis, R.M.; Milford, J.M. (2009). "Quantifying Avoided Fuel Use and Emissions from Solar Photovoltaic Generation in the Western United States." Environmental Science and Technology 43(1); 226-232.

Diao, R.; Lu, S.; Etingov, P.; Makarov, Y.V.; Ma, J.; Guo, X. (2011). NV Energy Solar Integration Study: Cycling and Movements of Conventional Generators for Balancing Services. PNNL-20594. Richland, WA: Pacific Northwest National Laboratory.

Ela, E.; Milligan, M.; Kirby, B. (2011). Operating Reserves and Variable Generation. NREL/TP-5500-51978. Golden, CO: National Renewable Energy Laboratory. 
Ela, E.; Diakov, V.; Ibanez, E.; Heaney, M. (2013). Impacts of Variability and Uncertainty in Solar Photovoltaic Generation at Multiple Timescales. NREL/TP-5500-58274. Golden, CO: National Renewable Energy Laboratory.

Environmental Protection Agency (EPA). (2011). Assessing the Multiple Benefits of Clean Energy. EPA-430-R-11-014. Washington, D.C.: EPA.

Etingov, P.V.; Makarov Y.V.; Ma, J.; Subbarao, K. (2012). Online Analysis of Wind and Solar Part I: Ramping Tool. PNNL-21112. Richland, WA: Pacific Northwest National Laboratory.

Finon, D.; Pignon, V. (2008). "Capacity Mechanisms in Imperfect Electricity Markets.” Utilities Policy 16 (3); 141-142.

Fu, W. (2012). "Reserve Capacities are Being 'Eaten Up."” China Energy. Beijing: Renmin Daily Press. Accessed December 2014: http://paper.people.com.cn/zgnyb/html/201211/19/content 1147498.htm.

Galloway, C.D.; Kirchmayer, L.K.; Marsh, W.D.; Mellor, A.G. (1960). “An Approach to Peak Load Economics." Power Apparatus and Systems, Part III. Transactions of the American Institute of Electrical Engineers 79 (3); pp. 527 -534.

Gao, C.; Li, Y. (2010). "Evolution of China's power dispatch principle and the new energy saving power dispatch policy." Energy Policy 38; pp. 7346-7357.

Hoff, T.E.; Perez, R.; Braun, G.; Kuhn, M.; Norris, B. (2006). The Value of Distributed Photovoltaics to Austin Energy and the City of Austin. Napa, CA: Clean Power Research.

Hoff, T.E.; Perez, R.; Ross, J.P.; Taylor, M. (2008). Photovoltaic Capacity Valuation Methods. SEPA Report No. 02-08. Washington, D.C.: Solar Electric Power Association.

HU Bin,LOU Suhua,LI Haiying, et al. (2015). "Spinning Reserve Requirements Estimating in Power System Integrated with Large Scale Photovoltaic Generation". Automation of Electric Power Systems.

Hummon, M.; Denholm, P.; Jorgenson, J.; Kirby, B.; Ma, O.; Palchak, D. (2013a). Fundamental Drivers of Operating Reserve Cost in Electric Power Systems. NREL/TP-6A20-58491. Golden, CO: National Renewable Energy Laboratory.

Hummon, M.; Weekley, A.; Searight, K.; Clark, K. (2013b). "Downscaling Solar Power Output to 4-Seconds for Use in Integration Studies." NREL/PR-6A20-60336. Golden, CO: National Renewable Energy Laboratory.

Ibanez, E.; Brinkman, G.; Hummon, M.; Lew, D. (2012). "A Solar Reserve Methodology for Renewable Energy Integration Studies Based on Sub-hourly Variability Analysis." 2nd Annual International Workshop on Integration of Solar Power into Power Systems Conference, 12-13 November 2012, Lisbon, Portugal. 
International Renewable Energy Agency (IRENA). (2012). Renewable Energy Technologies: Cost Analysis Series. Concentrating Solar Power. Accessed December 2014:

http://www.irena.org/documentdownloads/publications/re technologies cost analysis-csp.pdf.

Izquierdo, S.; Montañés, C.; Dopazo, C.; Fueyo, N. (2010). "Analysis of CSP plants for the definition of energy policies: The influence on electricity cost of solar multiples, capacity factors and energy storage." Energy Policy 38(10); pp. 6215-6221. Accessed December 2014: http://dx.doi.org/10.1016/j.enpol.2010.06.009.

Jorgenson, J.; Denholm, P.; Mehos, M.; Turchi, C. (2013). Estimating the Performance and Economic Value of Multiple Concentrating Solar Power Technologies in a Production Cost Model. NREL/TP-6A20-58645. Golden, CO: National Renewable Energy Laboratory.

Jorgenson, J.; Denholm, P.; Mehos, M. (2014). Estimating the Value of Utility-Scale Solar Technologies in California Under a 40\% Renewable Portfolio Standard. NREL/TP-6A2061685.

Keane, A.; Milligan, M.; DAnnunzio, C.; Dent, C.J.; Dragoon, K.; Hasche, B.; Holttinen, H.; Samaan, N.; Soder, L.; O’Malley, M. (2011). "Capacity Value of Wind Power." IEEE Transactions on Power Systems 26(2), 564-572.

Lew, D.; Brinkman, G.; Ibanez, E.; Hodge, B.M.; Hummon, M.; Florita, A.; Heaney, M. (2013). The Western Wind and Solar Integration Study Phase 2. NREL/TP-5500-55588. Golden, CO: National Renewable Energy Laboratory.

Lewis, J.; Wiser, R. (2005). Fostering a Renewable Energy Technology Industry: An International Comparison of Wind Industry Policy Support Mechanisms. LBNL-59116. Berkeley, CA: Lawrence Berkeley National Laboratory.

Li, D.; Gong, S.; Tian, F.; Zhao, L.; Xiao, F.; Man, Y. (2009). "The Feasibility and Policy Study on Developing Concentrating Solar Power in China." Beijing: Center for Clean Energy Technology, Chinese Academy of Sciences.

Li, P.; Cao, D. (2014). “Huge Market for Renewable Energy 'South-South Cooperation', China Has Become the Leader." Xinhua. Accessed December 2014: http://news.xinhuanet.com/fortune/2014-07/12/c 1111582382.htm.

Liu, H. (2013). "Ancillary Service: Next Breakthrough in Electricity Market Construction." China Energy. Beijing: Renmin Daily Press. Accessed March 2014: http://paper.people.com.cn/zgnyb/html/2013-01/07/content_1182626.htm.

Lu, S.; Etingov, P.V.; Diao, R.; Ma, J.; Samaan, N.A.; Makarov, Y.V.; Guo, X.; Hafen, R.P.; Jin, C.; Kirkham, H.; Shlatz, E.; Frantzis, L.; McClive, T.; Karlson, G.; Acharya, D.; Ellis, A.; Stein, J.; Hansen, C.; Chadliev, V.; Smart, M.; Saigo, R.; Sorensen, R.; Allen, B.; Idelchik, B. (2011). Large-Scale PV Integration Study. PNNL-20677. Richland, WA: Pacific Northwest National Laboratory. 
Macknick, J.; Newmark, R.; Heath, G.; Hallett, K.C. (2012). “Operational Water Consumption and Withdrawal Factors for Electricity Generating Technologies: A Review of Existing Literature." Environmental Research Letters 7(4): Article No. 045802.

Madaeni, S.; Sioshansi, R.; Denholm, P. (2013). "Estimating the Capacity Value of Concentrating Solar Power Plants with Thermal Energy Storage: A Case Study of the Southwestern United States.” IEEE Transactions on Power Systems 28(2); 1205-1215.

Madaeni, S.; Sioshansi, R.; Denholm, P. (2012). "How Thermal Energy Storage Enhances the Economic Viability of Concentrating Solar Power.” Proceedings of the IEEE 100(2); 335-347.

Madaeni, S.H.; Sioshansi, R.; Denholm, P. (2012). Comparison of Capacity Value Metrics for Photovoltaics in the Western United States. NREL/TP-6A20-54704. Golden, CO: National Renewable Energy Laboratory.

Makarov, Y.V.; Guttromson, R.T.; Huang, Z.; Subbarao, K.; Etingov, P.V.; Chakrabarti, B.B.; Ma, J. (2010). Wind Energy Management System EMS Integration Project: Incorporating Wind Generation and Load Forecast Uncertainties into Power Grid Operations. PNNL-19189. Richland, WA: Pacific Northwest National Laboratory.

Milligan, M.; Ela, E.; Hodge, B.M.; Kirby, B.; Lew, D.; Clark, C.; DeCesaro, J.; Lynn, K. (2011). Cost-Causation and Integration Cost Analysis for Variable Generation. NREL/TP-550051860. Golden, CO: National Renewable Energy Laboratory.

Mills, A.; Botterud, A.; Wu, J.; Zhou, Z.; Hodge, B-M.; Heany, M. (2013). Integrating Solar PV in Utility System Operations. ANL/DIS-13/18. Argonne, IL: Argonne National Laboratory.

Mills, A.; Wiser, R. (2012a). Changes in the Economic Value of Variable Generation at High Penetration Levels: A Pilot Case Study of California. LBNL-5445E. Berkeley, CA: Lawrence Berkeley National Laboratory.

Mills, A.; Wiser, R. (2012b). An Evaluation of Solar Valuation Methods Used in Utility Planning and Procurement Processes. LBNL-5933E. Berkeley, CA: Lawrence Berkeley National Laboratory.

National Energy Administration (NEA) of People’s Republic of China. (2014). "2013 Photovoltaic Power Generation Statistics.” NEA. Accessed December 2014: http://www.nea.gov.cn/2014-04/28/c 133296165.htm.

Navid, N.; Rosenwald, G.; Chatterjee, D. (2011). "Ramp Capability for Load Following in MISO Markets.” Midwest Independent System Operator.

National Development and Reform Commission (NDRC). (2007). State Environmental Protection Administration (SEPA), SERC, National Energy Working Group, "Pilot measures for implementing energy efficient dispatch《节能发电调度办法实施细则（试行）》”, No. 523.

NEA. (2014). "Response to Bill 2346 at the $2^{\text {nd }}$ Plenum of the $12^{\text {th }}$ People's Political Consultative Conference." Beijing: NEA. 
North American Electric Reliability Corporation (NERC). (2011). Methods to Model and Calculate Capacity Contributions of Variable Generation for Resource Adequacy Planning.Accessed December 2014: http://www.nerc.com/docs/pc/ivgtf/IVGTF1-2.pdf.

NERC. (2014). "Glossary of Terms Used in NERC Reliability Standards." Updated March 12, 2014. Accessed December 2014: http://www.nerc.com/files/glossary_of_terms.pdf.

National Renewable Energy Laboratory (NREL). (2014). "PVWatts: A Performance Calculator for Grid-Connected PV Systems.” Accessed March 2014:

http://rredc.nrel.gov/solar/calculators/pvwatts/version1/.

Palmintier, B.; Webster, M. (2014). "Impact of Operational Flexibility on Generation Planning." IEEE Transactions on Power Systems.

Pfeifenberger, J.; Spees, K.; Carden, K.; Wintermantel, N. (2013). Resource Adequacy Requirements Reliability and Economic Implications. Cambridge, MA: The Brattle Group and Astrape Consulting.

Pfeifenberger, J.; Spees, K.; Newell, S. (2012). Resource Adequacy in California Options for Improving Efficiency and Effectiveness. Cambridge, MA: The Brattle Group.

Public Service Company of Colorado (PSCO). (2011). 2011 Electric Resource Plan. Volume II: Technical Appendix. Denver, CO: PSCO.

Qu, C et al. (2014) "Optimizating Configuration of Spinning Reserve Based on Conditional Cost-Benefit Analysis." Electric System Automation 14: 010.

Servert J.; Wang, Z.; Martinez, D.; Zhu, L. (2012). “Technical Assistance Consultant's Report People's Republic of China: Concentrating Solar Thermal Power Development." Manila: The Asian Development Bank. Accessed December 2014: http://www.adb.org/sites/default/files/project-document/60107/43356-012-prc-tacr.pdf.

Short, W.; Packey, D.J.; Holt, T. (1995). Manual for the Economic Evaluation of Energy Efficiency and Renewable Energy Technologies. NREL/TP-462-5173. Golden, CO: National Renewable Energy Laboratory.

Shortt, A.; Kiviluoma, J.; O’Malley, M. (2013). “Accommodating Variability in Generation Planning." IEEE Transactions on Power Systems 28(1); 158-69.

Sioshansi, R.; Denholm, P.; Jenkin, T. (2012). "Market and Policy Barriers to Deployment of Energy Storage.” Economics of Energy and Environmental Policy 1(2); 47-63.

Sioshansi, R.; Denholm, P. (2013). "Benefits of Colocating Concentrating Solar Power and Wind.” IEEE Transactions Sustainable Energy 4(4); 877-885.

Sioshansi, R.; Denholm, P. (2010). "The Value of Concentrating Solar Power and Thermal Energy Storage.” IEEE Transactions on Sustainable Energy 1(3); 173-183. 
Sioshansi, R.; Madaeni, S.H.; Denholm, P. (2014). "A Dynamic Programming Approach to Estimate the Capacity Value of Energy Storage.” IEEE Transactions on Power Systems 29(1); 395-403.

State Council of People's Republic of China. (2014). Opinions on Several Major Policy Initiatives Supporting the Revitalization of Northeast China. Beijing: State Council.

State Council of People's Republic of China. (2015). Opinions on Further Deepening the Electric Power System Institution Reform. Beijing: State Council.

State Electricity Regulatory Commission (SERC). (2006). Measures on Management of Ancillary Services of Grid-Connected Power Plants.

SERC. (2007). Regulatory Measures for the Full Purchase of Renewable Energy, No. 25.

Sterling, J.; McLaren, J.; Taylor, M.; Cory, K. (2013). Treatment of Solar Generation in Electric Utility Resource Planning. NREL/TP-6A20-60047. Golden, CO: National Renewable Energy Laboratory.

Sullivan, P.; Eurek, K.; Margolis, R. (2014). Advanced Methods for Incorporating Solar Energy Technologies into Electric Sector Capacity-expansion Models: Literature Review and Analysis. NREL/TP-6A20-61185. Golden, CO: National Renewable Energy Laboratory.

Tuohy, A.; O’Malley, M. (2011). "Pumped Storage in Systems With Very High Wind Penetration." Energy Policy (39); pp. 1965-1974.

Usaola, J. (2012). "Operation of concentrating solar power plants with storage in spot electricity markets." IET Renewable Power Generation 6(1); 59-66.

Waldron, M. (2014). “Outlook for STE/ CSP deployment to 2018.” International Energy Agency (IEA). Accessed December 10, 2014:

http://www.iea.org/media/workshops/2014/solarelectricity/Waldron_SolarRoadmapWorkshop_S TECSPdeployment_Paris_Feb2014.pdf.

Wang, B.; Hobbs, B.F. (2013). "Flexiramp Market Design for Real-Time Operations: Can It Approach the Stochastic Optimization Ideal?" Proceedings of the 2013 IEEE Power and Energy Society General Meeting (PES), pp. 1-5.

Wang, Y. (2012). "Electricity Market Reform - Competitive Bidding Dispatch.” Economic and Trade Update Sum. No. 233, February.

Wilcox, S. (2012). National Solar Radiation Database 1991-2010 Update: User's Manual. NREL/TP-5500-54824. Golden, CO: National Renewable Energy Laboratory.

Xinhua News Agency. (2013). “China's First Concentrating Solar Power Project Connected to the Grid." State Grid Corporation of China. Accessed December 10, 2014: http://www.sgcc.com.cn/ywlm/mediacenter/industrynews/07/295307.shtml. 
Xcel Energy, Inc. (2013a). Costs and Benefits of Distributed Solar Generation on the Public Service Company of Colorado System. Minneapolis, MN: Excel Energy, Inc.

Xu, L.; Tretheway, D. (2012). Flexible Ramping Products: Draft Final Proposal. California Independent System Operator.

Xu, W. (2014). "New Clean Energy on the Rise, CSP to Explode." China Securities. Accessed December 2014: http://news.xinhuanet.com/energy/2014-10/14/c 1112815914.htm.

Zhang, G. (2013). "Review and Analysis of Ten Years of Electricity Sector Reform." China Economic Weekly. Accessed December 2014: http://www.ceweekly.cn/html/Article/38459.html.

Zhang, S. (2009). "Research on Pricing Mechanism of Bidding Price in Set with Energy Conservation Power Generation Dispatch.” Power System Technology. 33-19; 105-110.

Zhu, Y. (2014). "Concentrating Solar Power Meeting a Turn in Fortune.” Beijing: Caijing. August 11. Accessed December 2014: http://magazine.caijing.com.cn/2014-08$\underline{11 / 114336242 . h t m l}$. 